\title{
Carnes PSE (Pale, Soft, Exudative) e DFD (Dark, Firm, Dry) em lombo suíno numa linha de abate industrial \\ Meats PSE (Pale, Soft, Exudative) and DFD (Dark, Firm, Dry) \\ of an industrial slaughterline for swine loin
}

\author{
Magali Bernardes MAGANHINI ${ }^{1}$, Bruno MARIANO ${ }^{1}$, Adriana Lourenço Soares ${ }^{1}$, \\ Paulo D. GUARNIERI ${ }^{2}$, Massami SHIMOKOMAKI ${ }^{1}$, Elza Iouko IDA ${ }^{1 *}$
}

\section{Resumo}

A necessidade para uma maior produção de carne magra em suínos tem acarretado modificações nas características bioquímicas do músculo conduzindo ao desenvolvimento das anomalias nas suas cores, as denominadas carnes PSE e DFD. Estas carnes por apresentarem alterações de suas propriedades funcionais, resultam em grandes perdas econômicas. Nesse experimento, foram utilizadas 946 amostras de Longissimus dorsi m., lombos de suínos da linhagem Dalland, machos castrados e fêmeas, com 100 dias de idade, em um Frigorífico localizado na Região Sul do País. Os lombos foram classificados com base no valor de L ${ }_{24 \mathrm{he}} \mathrm{pH}_{24 \mathrm{~h}}$ Foi constatada uma incidência de $22,8 \%$ de carnes PSE, 1,0\% de DFD e 76,2\% de normal. Esses valores relativamente altos de carnes PSE mostram a necessidade de se realizar controles no seu manejo pré e pós-abate para a manutenção da qualidade da carne e evitar o excessivo prejuízo econômico dos frigoríficos decorrentes dessas anormalidades.

Palavras-chave: cor; pH; Longissimus dorsi m.; manejo pré e pós-abate.

\begin{abstract}
The needs of higher production of low fat pork have conducted changes on the muscle biochemical characteristics leading to color abnormality producing so-called PSE and DFD meats. The consequence is a relevant economical loss due to the impairment of meat functional properties. In this experiment, 946 samples of Longissimus dorsi $\mathrm{m}$. from barrows and gilts of Dalland lineage, of 100 days of age, were evaluated in a pork abattoir located in the south of Brazil. Samples were classified based on the $\mathrm{L}^{*}{ }_{24 \mathrm{~h} \mathrm{e}} \mathrm{pH}_{24 \mathrm{~h}}$ values. Results showed the occurrence of $22.8 \%$ of PSE meat, $1.0 \%$ de DFD meat and $76.2 \%$ of normal meat. These relatively higher values for PSE show undoubtedly the needs to carry out pre- and post-mortem management in order to maintain meat quality thus avoiding the excessive economic cost due to these meat abnormalities.
\end{abstract}

Keywords: color; pH; Longissimus dorsi; ante- and post-mortem management.

\section{Introdução}

A carne suína é hoje a proteína animal mais consumida no mundo, tendo ultrapassado a preferência dos consumidores pela carne bovina no ano de $1979^{9}$. Em 2007, a produção mundial de carne suína deverá ter incremento de $3,62 \%$, chegando a 103,39 milhões de toneladas. China, União Européia e Estados Unidos foram responsáveis por $81,3 \%$ da produção mundial em $2005^{2}$. A produção nacional de carne suína vem apresentando índices consideráveis de crescimento nos últimos 24 anos, em torno de 3,8\% ao ano ${ }^{1}$. O Brasil continua na posição de $4^{\circ}$ maior produtor mundial com 2,829 milhões de toneladas em 2006. Deste total, $81 \%$ foram consumidos no mercado interno $(30 \%$ in natura e $70 \%$ industrializada) e os $19 \%$ restantes tiveram como destino o mercado internacional ${ }^{2}$.

Na década de 1960, por exigência do consumidor, houve o direcionamento da produção de suínos para um aumento na produção de carne magra acarretando modificações substanciais tanto na composição proximal como nas características bioquímicas do músculo. Posteriormente, constataram-se

\footnotetext{
Programa de Pós-graduação em Ciência de Alimentos

Departamento de Ciência e Tecnologia de Alimentos,

Centro de Ciências Agrárias, Universidade Estadual de Londrina-UEL,

CP 6001, CEP 86051-970, Londrina - PR, Brasil

E-mail:elida@uel.br

2 Programa de Pós Graduação em Ciência dos Alimentos,

Faculdade de Ciências Farmacêuticas, Universidade de São Paulo - USP,

São Paulo - SP, Brasil

${ }^{*}$ A quem a correspondência deve ser enviada
}

que essas alterações foram provocadas por uma mutação genética na proteína reguladora do fluxo de cálcio, rianodina, provocando o surgimento do PSS (sigla inglesa de Pork Stress Syndrome) ou Síndrome do Estresse Suíno com o conseqüente comprometimento na qualidade pela formação das carnes PSE (sigla inglesa de Pale, Soft e Exudative), o que significa Pálida, Macia e Exsudativa. Estas carnes apresentam variações em suas colorações e alterações de suas propriedades funcionais, sendo um dos maiores problemas enfrentados pela indústria processadora, com conseqüentes perdas econômicas calculadas, preliminarmente, em cerca de US\$ 4,5 mi ${ }^{15}$. MURRAY e JOHNSON $^{14}$ relataram que cada chuleta de carne suína PSE perde aproximadamente $3 \%$ mais água do que a carne normal na embalagem no varejo, e estimaram que a condição PSE diminuiu o valor de um suíno em 5 dólares Canadenses. Assim, atenção especial por parte da indústria em monitorar a qualidade do manejo dos suínos desde a genética até o produto final são fatores decisivos para garantir a qualidade da carne.

A carne PSE representa o principal problema de qualidade na indústria de carne suína, devido às suas características como baixa capacidade de retenção de água, textura flácida e cor pálida que levam às elevadas perdas de água durante o processamento. A carne PSE é indesejável tanto para os consumidores como para a indústria de processamento e a principal causa do desenvolvimento da condição carne PSE é uma decomposição acelerada do glicogênio após o abate, que causa um valor de $\mathrm{pH}$ muscular baixo, geralmente inferior a 
5,8 , enquanto a temperatura do músculo ainda esta próxima do estado fisiológico $\left(>38{ }^{\circ} \mathrm{C}\right)$, acarretando um processo de desnaturação protéica comprometendo as propriedades funcionais da carne ${ }^{8}$.

A incidência de carnes PSE está relacionada com os fatores pré-abate como genética, nutrição e manejo. $\mathrm{O}$ gene da rianodina também conhecido como gene halotano destaca-se como o responsável pela produção de carcaças com maior percentagem de carne magra, porém este conduziu à maior predisposição ao estresse, levando à produção de carne $\mathrm{PSE}^{7}$. As linhagens genéticas que foram melhoradas para o ganho de peso e produção de carne magra apresentaram ocorrência elevada para a síndrome do PSE devido ao metabolismo energético insuficiente. Assim, as empresas de melhoramento genético têm procurado revertê-lo, tentando eliminar o gene halotano dos animais.

Com relação à nutrição, a suplementação na dieta com vitamina $\mathrm{E}$ e triptofano inibiu o desenvolvimento de carnes PSE ${ }^{15}$. Dentro de manejo, alguns parâmetros merecem destaque como tempo de transporte dos animais da granja para o frigorífico, temperatura ambiental durante o transporte, apanha e coleta dos animais, destacando a inclinação da rampa que deve ser inferior a $20^{\circ}$, jejum pré-abate e tempo de descanso dos animais antes do abate ${ }^{15}$. Os prejuízos econômicos da carne PSE estão relacionados com a sua utilização na elaboração de produtos cárneos, sendo que esta carne pode ser destinada até certo limite para a elaboração de alguns produtos fermentados e certos tipos de emulsionados, mas é inadequada para elaboração de presunto cozido e outros produtos curados cozidos devido ao comprometimento das propriedades funcionais das suas proteínas ${ }^{17}$.

O desenvolvimento da carne DFD também está relacionado com o manejo pré-abate. Os exercícios físicos, o transporte, a movimentação, o jejum prolongado e o contato com suínos estranhos ao seu ambiente acarretam o consumo das reservas de glicogênio, levando à lentidão da glicólise com relativa diminuição da formação de ácido lático muscular. $\mathrm{O}$ pH reduz ligeiramente nas primeiras horas e depois se estabiliza, permanecendo em geral em níveis superiores a 6,013. Em decorrência do $\mathrm{pH}$ alto, as proteínas musculares conservam uma grande capacidade para reter água no interior das células e, como conseqüência, a superfície de corte do músculo permanece pegajosa e escura ${ }^{10,15}$. A carne DFD pode ser utilizada para o processamento de produtos emulsionados como salsicha tipo Frankfurt e produtos curados cozidos, formulados com $60 \%$ de carne normal para que seja obtida uma coloração desejável, não sendo recomendada para o processamento de produtos fermentados e $\operatorname{secos}{ }^{17}$. Portanto, tendo em vista os eventuais prejuízos econômicos dessas carnes anormais, o presente trabalho teve como objetivo investigar a ocorrência de PSE e DFD na carne suína em frigorífico localizado na Região Sul do País.

\section{Material e métodos}

Neste experimento, foram utilizados 946 lombos (músculo Longissimus dorsi) provenientes de suínos da linhagem Dalland, machos castrados e fêmeas, com 100 dias de idade de um Frigorífico da Região Sul de grande representativida- de no setor. Os suínos foram abatidos através do processo convencional com insensibilização elétrica, sangria, com os animais erguidos, escaldagem em água a 59,4 ${ }^{\circ} \mathrm{C}$, evisceração e toalete final. As carcaças permaneceram por 24 horas em câmara frigorífica a $0,0 \pm 1{ }^{\circ} \mathrm{C}$ e o músculo Longissimus dorsi foi removido para as análises de $\mathrm{pH}$ e cor.

As amostras foram avaliadas com relação aos valores de pH com o potenciômetro Sentron 1001 e a medida de cor com colorímetro Gardner 45/0 com iluminante D65 expressa pelo sistema de cor CIELAB ( $\mathrm{L}^{*}$-luminosidade, a*- componente vermelho-verde, $b^{*}$ - componente amarelo-azul). O valor de $\mathrm{L}^{*}$ foi utilizado como parâmetro para classificação dos lombos em DFD, PSE e Normal conforme recomendações de CHANNON, PAYNE, WARNER ${ }^{5}$ e WARRIS e BROWN ${ }^{16}$. Lombos com valores de $\mathrm{L}^{*}{ }_{24 \mathrm{~h}}>53$ foram classificados como PSE, com L ${ }_{24 \mathrm{~h}}^{*}<$ 45 como DFD e com valores intermediários $45 \leq \mathrm{L}^{*}{ }_{24 \mathrm{~h}} \leq 53$ como Normal.

\section{Resultados e discussão}

A Figura 1 apresenta o histograma de distribuição do valor de $\mathrm{L}^{*}{ }_{24 \mathrm{~h}}$ das amostras de lombo suíno. Observa-se que estas apresentaram uma distribuição tipicamente normal com ampla variação de luminosidade (de 40 a 62). A presença de amostras nos dois extremos de valor de $\mathrm{L}^{*}{ }_{24 \mathrm{~h}}$ associada ao do $\mathrm{pH}_{24 \mathrm{~h}}$ sugere o aparecimento de carnes DFD e PSE.

Com base nos resultados obtidos, foi possível estimar a incidência de PSE de 22,83\% e DFD de 1,06\% valores apresentados na Figura 2. Resultados diferentes foram relatados por CULAU et al. ${ }^{6}$ que identificaram uma freqüência de 30,69\% de carcaças PSE no Estado do Rio Grande do Sul e ANDRADE et al. ${ }^{3}$ que encontraram uma freqüência de carcaças PSE de 17,2\% e de DFD 13,4\% no oeste do Paraná. Já no Canadá, aproximadamente $13 \%$ dos lombos suínos foram $\mathrm{PSE}^{14}$, e nos EUA, apesar da PSE já ser identificada há muito tempo, em 1963 a incidência era de $18 \%$, diminuindo para $16 \%$ em $1992^{4}$.

O valor de $\mathrm{pH}$ entre as amostras PSE, DFD e Normal diferiram significativamente entre si ( $\mathrm{p} \leq 0,05)$ (Tabela 1). O maior valor de $\mathrm{pH}$ foi observado obviamente para os lombos DFD e o menor para os PSE, sendo semelhante aos obtidos por outros autores ${ }^{5,11,12}$. O valor de $\mathrm{a}^{*}{ }_{24 \mathrm{~h}}$ (vermelho) não diferiu significativamente ( $\mathrm{p} \leq 0,05)$ entre as amostras de lombo PSE, DFD e Normal, enquanto que, para o componente b* ${ }_{24}$ (amarelo), o maior valor foi observado para os lombos PSE, seguidos pelo Normal e DFD.

Uma correlação negativa significativa foi encontrada $(\mathrm{R}=$

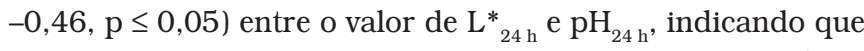
quanto menor o $\mathrm{pH}$ maior a luminosidade, ou seja, mais pálido apresenta-se o lombo e vice-versa. O valor de $\mathrm{L}^{*}{ }_{24 \mathrm{~h}}$ correlacionou-se positivamente e significativamente $(R=0,43, p \leq 0,05)$ com o valor de $\mathrm{b}_{24 \mathrm{~h}}$, com um aumento de luminosidade associada com o aumento de valor de $\mathrm{b}^{*}{ }_{24 \mathrm{~h}}$, indicando que lombos mais pálidos são também mais amarelos. Esses resultados são semelhantes aos de LEACH et al. ${ }^{12}$, que reportaram que as carnes PSE apresentaram maior valor de $\mathrm{L}^{*}, \mathrm{a}^{*} \mathrm{e} \mathrm{b}^{*}$ do que as carnes Normais. 


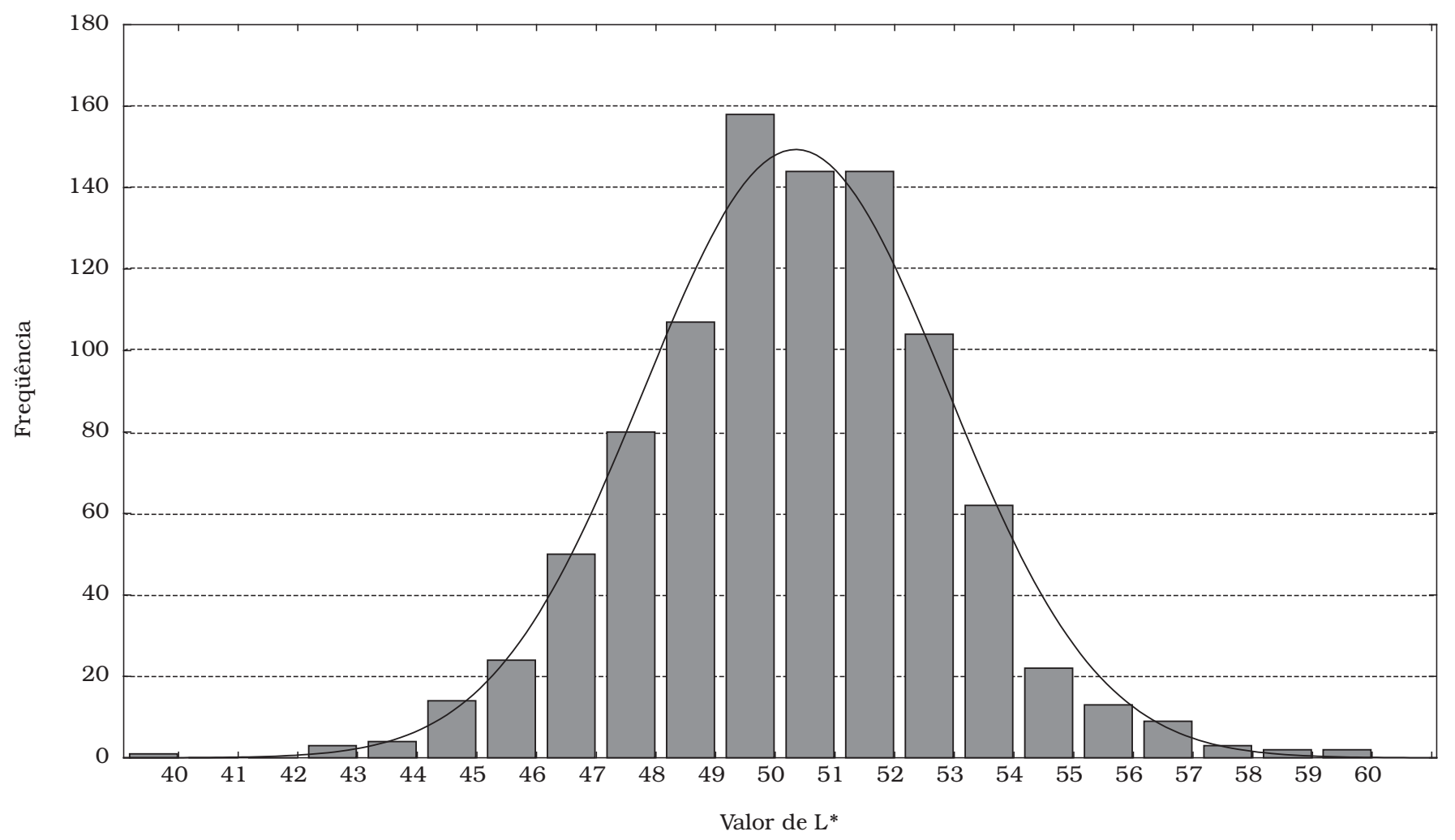

Figura 1. Histograma de distribuição do valor de $\mathrm{L}^{*}{ }_{24 \mathrm{~h}}$ para os lombos suínos.

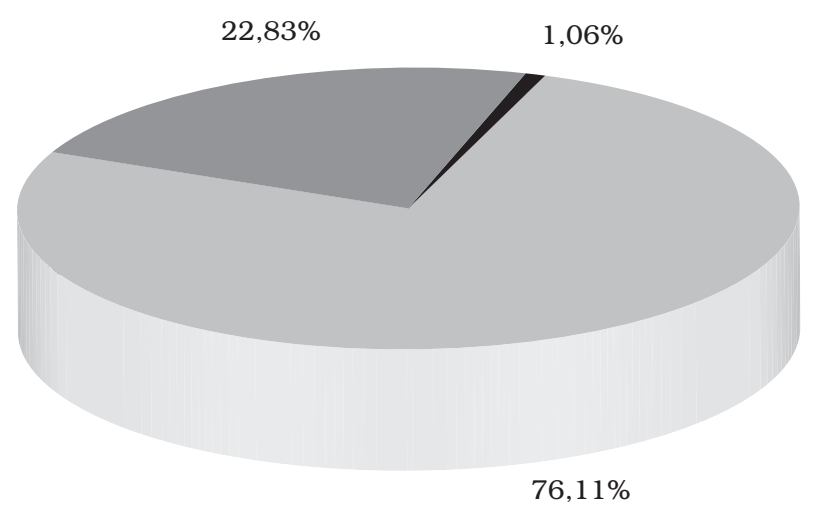

Figura 2. Ocorrência de PSE e DFD em amostras de lombo suíno.

\section{Conclusão}

Os resultados obtidos não oferecem condições para estabelecer se há tendências em diminuir ou aumentar a ocorrência da incidência de carnes PSE nos rebanhos suínos dadas as inúmeras variáveis que conduzem à sua formação. Entretanto esse estudo revela a necessidade premente de se realizar um acompanhamento sistemático na cadeia produtiva desses animais com a finalidade de obter um padrão de manejo para, com esse diagnóstico, estabelecer procedimentos sistemáticos e, dessa forma, implantar um controle nos processos para obtenção das carnes suínas evitando prejuízos econômicos aos frigoríficos.
Tabela 1. Valores de $\mathrm{pH}, \mathrm{L}^{*}, \mathrm{a}^{*} \mathrm{e} \mathrm{b} \mathrm{b}^{*} 24$ horas post mortem para lombos suínos classificados como PSE, DFD e Normal.

\begin{tabular}{|c|c|c|c|c|}
\hline & $\mathrm{pH}$ & $\mathrm{L}^{*}$ & $\mathrm{a}^{*}$ & $\mathrm{~b}^{*}$ \\
\hline PSE & $5,46^{c} \pm 0,10$ & $54,43^{\mathrm{a}} \pm 1,46$ & $1,15^{a} \pm 0,76$ & $8,48^{a} \pm 0,88$ \\
\hline Normal & $5,52^{\mathrm{b}} \pm 0,10$ & $50,34^{\mathrm{b}} \pm 1,77$ & $1,34^{\mathrm{a}} \pm 1,23$ & $7,93^{\mathrm{b}} \pm 0,97$ \\
\hline DFD & $5,80^{\mathrm{a}} \pm 0,16$ & $43,95^{c} \pm 1,34$ & $1,17^{\mathrm{a}} \pm 0,74$ & $6,37^{\mathrm{c}} \pm 0,63$ \\
\hline
\end{tabular}

a $5 \%$ de probabilidade.

\section{Agradecimentos}

MBM, BM, ALS são bolsistas de Pós Graduação da Fundação CAPES, IC do CNPq e Pós-Doutorado do CNPq, respectivamente. MS e EII são bolsistas de produtividade do CNPq.

\section{Referências bibliográficas}

1. ABCS - Associação Brasileira dos Criadores de Suínos. Disponível em: http://www.abcs.com.br. Acesso em 19 de junho de 2005.

2. ABIPECS - Associação Brasileira da indústria Produtora e Exportadora da Carne Suína. Disponível em: http://www.abipecs. org.br . Acesso em 16 de dezembro de 2006.

3. ANDRADE, J.; REMY, C.; NICOLAIEWSKY, S.; OURIQUE, J. M. R.; CULAU, P. O. V.; BRESSAN, M. C. Levantamento e análise de alguns fatores pré e pós abate determinantes de anomalias na qualidade da carne suína. I Efeito da distancia granja-frigorífico, tempo de descanso, sexo e peso vivo. In: VI Congresso Brasileiro de Veterinários Especialistas em Suínos, 1993, Goiânia-GO, p. 132. 
4. CASSENS, R.G. Historical perspectives and current aspects of pork meat quality in the USA. Food Chem., v. 69, n. 4, p. 357-363, 2000 .

5. CHANNON, H. A.; PAYNE, A. M.; WARNER, R. D. Halothane genotype, pre-slaugther handling and stunning method all influence pork quality. Meat Sci., v. 56, n. 3, p. 291-299, 2000.

6. CULAU, P. O. V.; OURIQUE, J. M. R.; NICOLAIEWSKY, S.; BRESSAN, M. C. Incidence of PSE in commercial pig carcasses in Rio Grande do Sul State, Brazil. Boletim Técnico da Associação Sul Brasileira das Indústrias de Produtores de Suínos, Porto Alegre, 1994.

7. CULAU, P. O. V.; LÓPEZ, J.; RUBENSAM, J. M.; LOPES, R. F. F.; NICOLAIEWSKY, S. Influência do gene halotano sobre a qualidade da carne. R. Bras. Zoot., v. 31, n. 2, p. 954-961, 2002.

8. D'SOUZA, D. N.; DUNSHEA, F. R.; WARNER, R. D.; LEURY, B.J. The effect of handling preslaughter and carcass processing rate post-slaughter on pork quality. Meat Sci., v. 50, n. 4, p. 429-437, 1998.

9. ELAM, T. E. The world pork industry-rapid change and restructurinr implications for a global pork makket. In: Elanco Animal Health International Symposium. Indianápolis, Indiana, EUA, 1997.

10. FELÍCIO, P. E. O ABC do PSE/DFD. Aliment. Tecnol., v. 2, n. 10, p. 54-57, 1986.
11. JENSEN, P.; BARTON-GADE, P. A. Performance and carcass characteristics of pigs with know genotypes for halothane susceptibility. In: Commission on Animal Management and Health and Comission of Pig Production, Wageningen, p. 80-93, 1985.

12. LEACH, L. M.; ELLIS, M.; MCKEITH, F. K.; WILSON, E. R. The growth performance, carcass characteristics, and meat quality oh halothane carrier and negative pigs. J. Anim. Sci., v. 74, n. 5, p. 934-943, 1996.

13. LENGERKEN, G.; MAAK, S.; WICKE, M. Muscle metabolism anda meat quality of pigs and poultry. Veterinrija Ir Zootechinika, v. 42, p. 82-86, 2002.

14. MURRAY, A. C.; JOHSONS, C. P. Impact of the gene on muscle quality and pre-salaughter deaths in Western Canadian pigs. J. Anim. Sci., v. 78, n. 4, p. 543-548, 1998.

15. ODA, S. H. I.; BRIDI, A. M.; SOARES, A. L.; GUARNIERI, P. D.; IDA, E. I.; SHIMOKOMAKI, M. Carnes PSE (Pale, Soft, Exudative) e DFD (Dark, Firm, Dry) em aves e suínos - diferenças e semelhanças. Rev. Nac. Carne, v. 28, n. 325, p. 108-113, 2004.

16. WARRIS, P. D; BROWN, S. N. The relationships between initial $\mathrm{pH}$, reflectance and exudation in pig muscle. Meat Sci., v. 20 , n. 1, p. 65-74, 1987.

17. WIRTH, F. Technologie der Verabeitung von flaisc mit abweichender Beschaffenhert. Fleischirwtschaft, v. 65, p. 998-1001, 1986. 